$17^{\text {th }}$ International Congress of Metrology, 08006 (2015)

DOI: $10.1051 /$ metrology / 201508006

(C) Owned by the authors, published by EDP Sciences, 2015

\title{
Measurement requirements for biogas specifications
}

\author{
Adriaan M.H. van der Veen ${ }^{1, a}$, Andrew S. Brown ${ }^{2}$, Jianrong Li ${ }^{1}$, Arul Murugan ${ }^{2}$, Martti Heinonen ${ }^{3}$, Frédérique Haloua ${ }^{4}$ and \\ Karine Arrhenius ${ }^{5}$ \\ ${ }^{1}$ VSL, Thijsseweg 11, 2629 JA Delft, the Netherlands \\ ${ }^{2}$ National Physical Laboratory (NPL), , Teddington, Middlesex, TW11 OLW, United Kingdom \\ ${ }^{3}$ Centre for Metrology MIKES, VTT Technical Research Centre of Finland Ltd., Tekniikantie 1, 02151 Espoo, Finland

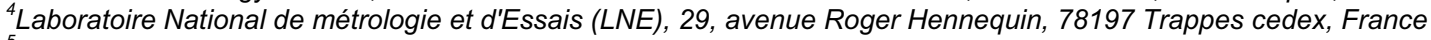 \\ ${ }^{5}$ SP Sveriges Tekniska Forskningsinstitut AB (SP), Chemistry, Materials and Surfaces, Box 857, SE-501 15 Borås, Sweden
}

\begin{abstract}
The increased use of biogas and biomethane urgently requires that these non-conventional energy gases can be transmitted through natural gas grids and refuelling stations. The European Standardization Organisation CEN is developing specifications for green gas which supplement the specifications for natural gas. The specifications for green gas address a range of parameters not commonly covered in natural gas, such as the contents of impurities (e.g., siloxanes, ammonia, halogenated hydrocarbons, and hydrogen chloride), dust content and particles. In a collaboration between 12 European metrology institutes and 3 university groups, robust and reliable methods are developed to support these draft specifications and to enable conformity assessment. The project also deals with issues related to density, calorific value, moisture content, and the sampling of biogas. This paper gives an overview of the state-ofthe-art in green gas testing, as well as an outlook what methods need be developed.
\end{abstract}

\begin{abstract}
Résumé. L'augmentation de l'utilisation de biogaz et de biométhane exige impérativement que ces gaz énergétiques non conventionnels puissent être transmis aux réseaux de gaz naturel et aux stations-services. Le Comité Européen de Normalisation CEN développe actuellement des spécifications pour le « gaz vert » qui complètent les spécifications pour le gaz naturel. Les spécifications pour le «gaz vert» concernent une gamme de paramètres habituellement non traités pour le gaz naturel tels que les teneurs en impuretés (par exemple les siloxanes, l'ammoniac, les hydrocarbures halogénés, et le chlorure d'hydrogène), les poussières et les particules. Dans une collaboration entre 12 instituts de métrologie européens et 3 groupes universitaires, des méthodes robustes et fiables sont développées pour appuyer ces projets de spécifications et pour permettre une évaluation en conformité. Le projet traite également des questions liées à la densité, au pouvoir calorifique, à la teneur en humidité et à l'échantillonnage du biogaz. Cet article donne un aperçu de l'état-de l'art des études sur les «gaz verts» ainsi qu'une perspective sur les méthodes qui doivent être développées.
\end{abstract}

\section{Introduction}

As natural gas resources are declining and the EU depends increasingly on imported natural gas, diversification of the European natural gas supply is underway as required by the Renewable Energy Directive 2009/28/EC [1] and EC targets, which specify that $20 \%$ of EC energy consumption should come from renewable sources by 2020 , and that biofuels should provide at least $10 \%$ of transport petrol and diesel consumption by the same year. There is now an urgent need to significantly increase the amount of biogas which is injected into natural gas networks.

The Renewable Energy Directive 2009/28/EC [1] establishes a framework for the promotion of energy from renewable sources, thus reducing $\mathrm{CO}_{2}$-emissions and securing the supply of energy in the European Union. In its clause (2), the use of renewable energy in the transport sector is referred to as a means to reduce the EU's dependence on fossil fuels. Furthermore, in clause (57) the need to integrate renewable energy into existing transmission and distribution grids is stated. The use of agricultural material $[1$, clause (12)] is identified as having a high potential for greenhouse gas emission reduction and for having significant environmental advantages at the same time.

To promote the use of biomethane as required by the EC Directive concerning common rules for the internal market in natural gas $(2003 / 55 / E C)$ [5], specifications

\footnotetext{
$\overline{{ }^{a} \text { Corresponding author: avdveen@ }}$ vsl.nl
} 
have been developed for the injection of biomethane into the natural gas transport and distribution grids and for use as transport fuels. Access to the natural gas grids and fuelling stations is essential for the promotion of biomethane.

To support the use of green gas, the European Commission has issued mandate M/475 [3] to CEN, the European Organisation for Standardisation, concerning the specifications for upgraded biogas and biomethane for injection into natural gas grids and for use as transport fuel. This mandate was issued to facilitate the market penetration of biomethane through the development of a European Standard for a quality specification for biomethane. The development of these specifications (prEN 16723-1 [6] for grid injection and prEN 16723-2 [7] for refuelling stations) is well underway.

For the implementation of such specifications, metrologically traceable methods and reference materials are required to ensure that measurements of the relevant properties of biogas are robust and reliable. For a substantial number of parameters, such methods and reference materials are lacking. Reliable measurement results with stated uncertainties are a prerequisite for assessing conformity with the aforementioned specifications for biogas. This conformity assessment is a prerequisite for the trade and use of biogas and biomethane.

\section{Biogas specifications}

The draft specifications prEN 16723-1 [6] for grid injection and prEN 16723-2 [7] for refuelling stations contain for a number of parameters specifications:

1) Silicon content

2) Compressor oil content

3) Dust content

4) Chlorine content

5) Fluorine content

6) Polycyclic aromatic hydrocarbon content

7) Ammonia content

8) Amine content

9) Hydrogen cyanide content

10) Hydrogen sulphide and carbonyl sulphide content

With respect to other properties, these specifications refer to the H-gas specification for natural gas [8], which is developed under mandate $\mathrm{M} / 400$ from the European Commission to CEN. For most of the impurity contents, maximum permissible levels are still being discussed. The draft specifications [6,7] take the view that these limits should be based on requirements with respect to the integrity of the natural gas infrastructure, including appliances, and the safety of end users. For many parameters, the specification is that the biomethane and upgraded biogas should be "technically free". This condition can be met in most cases by installing facilities for removal of impurities, or groups of impurities.

The silicon content is one of the parameters for which a maximum level is given $\left(0.5 \mathrm{mg} \mathrm{m}^{-3}\right.$ under normal conditions), just as fluorine content $\left(3.5 \mathrm{mg} \mathrm{m}^{-3}\right)$ and chlorine content $\left(1 \mathrm{mg} \mathrm{m}^{-3}\right)$.

In response to the development of these specifications, a project has been defined in the European
Metrology Research Programme (EMRP) to address the needs for measurement standards and reference methods. This project (EMRP ENG54 - Metrology for biogas) [10] aims to develop and validate methods for determining key impurities, moisture, particulates, calorific value, and density:

- Reference methods for the measurement of the contents of key impurities in biogas and biomethane: total silicon and siloxanes, sulphurcontaining compounds, aromatic hydrocarbons, halogenated hydrocarbons, ammonia, hydrogen cyanide, hydrogen chloride and carbon monoxide;

- Capabilities for the measurement of the particulate content and water content;

- Methods for the measurement of the calorific value, heat capacity, and density;

- A traceable method for determining the concentration of biomethane in samples of blended biomethane and natural gas;

- Methods for sampling biogas and biomethane in the field.

Ultimately, these methods can be used for, e.g., the development and delivery of certified reference materials, quality assurance schemes, including proficiency tests, calibrations, and the development of standardised test methods. These tools are essential for reliable, reproducible and accurate measurement, which in turn is essential for conformity assessment. For implementing the specifications, it is important that methods are available that are dedicated for assessing the quality of biomethane and upgraded biogas. Currently, these methods are lacking, and the draft specifications refer either to methods developed for air quality or methods not having been validated for biogas [6,7]. In the European Metrology Programme for Innovation and Research (EMPIR), a call has been published for the development and drafting of standardised test methods for biomethane and upgraded biogas [9] to fill this void. In this paper, the approaches chosen in ENG54 "Metrology for biogas" to meet the objectives are described, together with the first results.

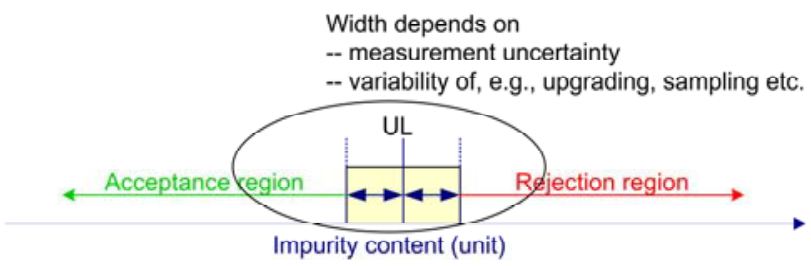

Figure 1. Assessment of compliance for an impurity content, and a specified upper limit (UL). The case shown is for a 50\%:50\% sharing of the risk

Assessment of compliance with respect to regulatory limits [12] requires knowledge about, among others, the measurement uncertainty associated with the results, the sharing of the risks, and the probability level (see figure $1)$.

\section{Impurities}

\subsection{Siloxanes}


In the EMRP project ENG01 "Characterisation of Energy Gases" [11], work on the development of measurement standards for siloxanes was already started. The results were promising, but indicated at the same time that substantially more work was needed. The work on siloxanes is continued in the ENG54 project. Two kinds of reference methods are being developed: one that measures the contents of the various siloxanes in biogas, and another that addresses the total silicon content. In principle, only the total silicon content is of relevance for the biogas specifications [6,7].

The work on the various siloxanes is for a number of reasons relevant in view of the objectives of the project. The behaviour of the siloxanes in gas mixtures in cylinders differs from compound to compound (see figure 2), so in order to understand the issues regarding the stability of the gas mixtures over time, data about the specific compounds is necessary. Furthermore, many environmental and air quality laboratories have already gas chromatographs (GCs) equipped with a mass spectrometer (MS) or flame ionisation detector (FID), so that one of the candidate methods for standardisation as field method would be a GC/MS or GC/FID method, and then calculating the total silicon content.

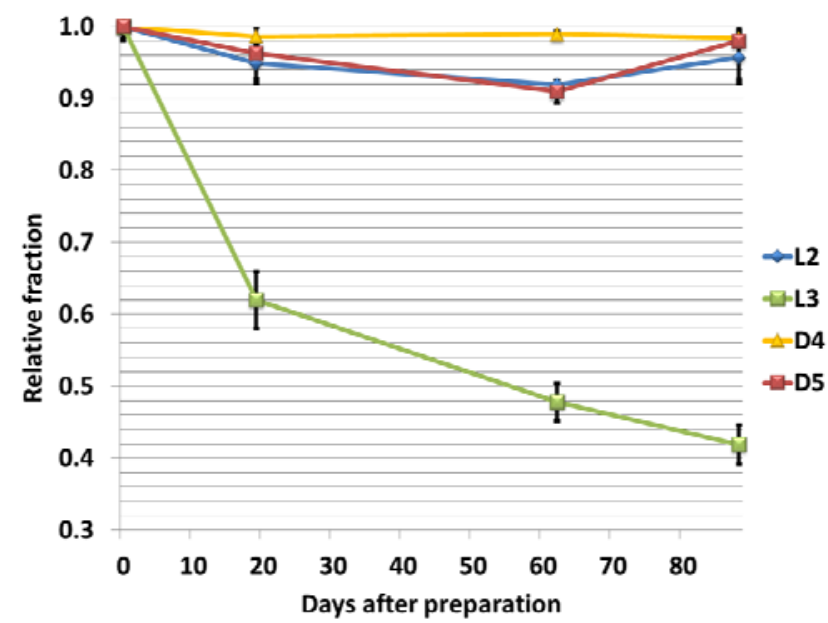

Figure 2. Stability of various siloxanes in methane in passivated gas cylinders [14]

\subsection{Sulphur-containing species}

Established reference methods and measurement standards for components like hydrogen sulphide [13], methyl mercaptan and ethyl mercaptan [15] already exist, although those for hydrogen sulphide have not been established in methane or biogas, but in nitrogen. At the same time, various national metrology institutes (NMIs) maintain primary standard gas mixtures (PSMs) for sulphur-containing species in methane.

Biogas is usually saturated with moisture and for testing equipment for measuring the sulphur content of untreated biogas, having CRMs certified for sulphur content in the presence of water is important. One of the critical factors is the stability of such mixtures. It is well known in the gas analysis area that water is a facilitator of many mechanisms and is expected to have an effect on the stability of such CRMs. The feasibility of producing such CRMs is assessed.

\subsection{BTEX and PAH}

At the time of drafting the project proposal, the contentof BTEX (benzene, toluene, ethylbenzene, xylenes) was in the draft specification, but these have subsequently been removed. Nevertheless, methods for these compounds are developed, because (1) there is a lot of experience in determining the contents of these components, (2) these compounds can be viewed as representative for a much larger group of volatile organic compounds (VOCs), and (3) having validated reference methods and measurement standards is a great aid in assessing the performance of dynamic preparation techniques for gas mixture preparation, such as described in ISO 6145 [16]. These preparation methods are of particular importance for the development of measurement standards for reactive components, such as ammonia (section 3.5), hydrogen cyanide (section 3.6), and hydrogen chloride (section 3.7). For most of the other types of measurement standards for impurities, static gravimetry (ISO 6142 [17]) is used to produce calibration gas mixtures in cylinders.

For PAHs (polycyclic aromatic hydrocarbons), reference methods are developed for analysing biogas samples. Preparing gas mixtures using static gravimetry is not feasible, because of the low vapour pressure and the strong adsorption of these compounds on cylinder surfaces. Various dynamic preparation techniques have shown in the past to be suitable for developing measurement standards of these compounds in nitrogen and air [16]. These methods are further developed to be suitable for upgraded biogas and biomethane.

\subsection{Halogenated hydrocarbons}

Chlorine and fluorine atoms occur in different compounds in biogas. On one hand there are $\mathrm{HF}$ and $\mathrm{HCl}$, whereas on the other many halogenated hydrocarbons occur.

For selected halogenated hydrocarbons, measurement standards are developed using static gravimetry. Five commonly encountered compounds have been chosen: dichloromethane, tetrachloroethylene, 1,4dichlorobenzene, 1,1,2-trichloro-1,2,2-trifluoroethane, dichlorodifluoromethane. The reference methods will be mostly based on various configurations of GC/MS or GC/AED (AED = atomic emission detector).

A method for total chlorine or total fluorine content is not foreseen in the ENG54 Biogas project - the challenges of measuring total halogenates in a traceable metrologically-robust fashion for different application has recently been discussed elsewhere [18] .

\subsection{Ammonia}

The determination of ammonia in biogas is challenging not only because of the reactivity of ammonia, but also because most measurement techniques are based on infrared spectroscopy. Whereas for ammonia in air or nitrogen these techniques have not interferences from the matrix, the same cannot be said for biogas. Both carbon dioxide and methane are infrared active, so that most 
commercial analysers are not performing well for ammonia in biogas. The first measurements with Fouriertransform infrared (FTIR) and cavity enhanced absorption spectroscopy (CEAS) have demonstrated the feasibility of determining the ammonia content in biomethane and upgraded biogas with limited effects of interferences (see figure 3).
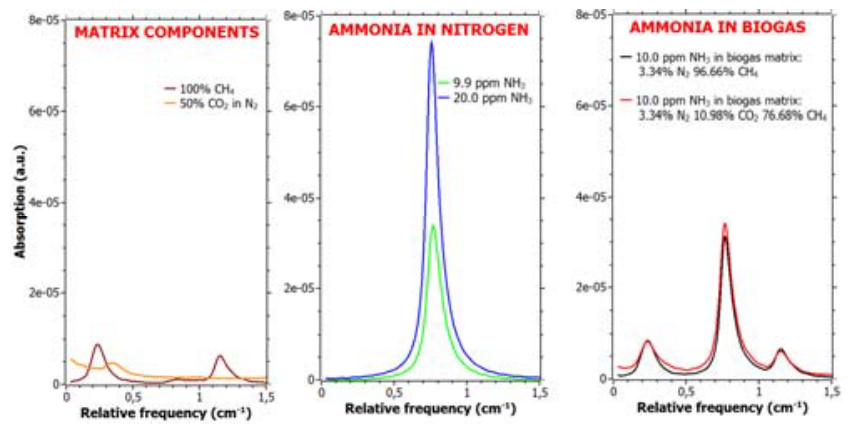

Figure 3. Biogas background (left), ammonia in nitrogen absorption peak (middle) and ammonia in nitrogen spectrum (right) on a CEAS spectrometer [19]

Measurement standards can be realised both using static gravimetry as well as with dynamic gas mixture preparation methods.

\subsection{Hydrogen cyanide}

The metrology for hydrogen cyanide is not very well developed yet. The component is reactive and causes stability issues. Hydrogen cyanide is easily detectable with a dedicated cavity ring down spectrometer (CRDS) [20]. As with ammonia, the biogas matrix causes interferences (see figure 4), but there are absorption bands of $\mathrm{HCN}$ with limited interferences.

Because of the stability issues with $\mathrm{HCN}$ in cylinders, a permeation method is under development for generating gas mixtures with a known fraction $\mathrm{HCN}$. The method will be configured in such a way that it operates on a gravimetric basis to enhance the performance of the gas mixture preparation.

\subsection{Hydrogen chloride}

$\mathrm{HF}$ is not included in the scope of the ENG54 Biogas project, but $\mathrm{HCl}$ is. One of the issues with $\mathrm{HF}$ is that it is very difficult to handle and very aggressive with respect to valves, tubing and measurement equipment. $\mathrm{HCl}$ is causing less corrosion problems, in particular in the absence of water.

The approach for determining the hydrogen chloride content is broadly the same as for ammonia and hydrogen cyanide. Apart from CRDS, also Ion Mobility Spectroscopy (IMS) will be used in the validation work. A first series of measurements

Measurement standards are being developed using static and dynamic gas mixture preparation techniques.

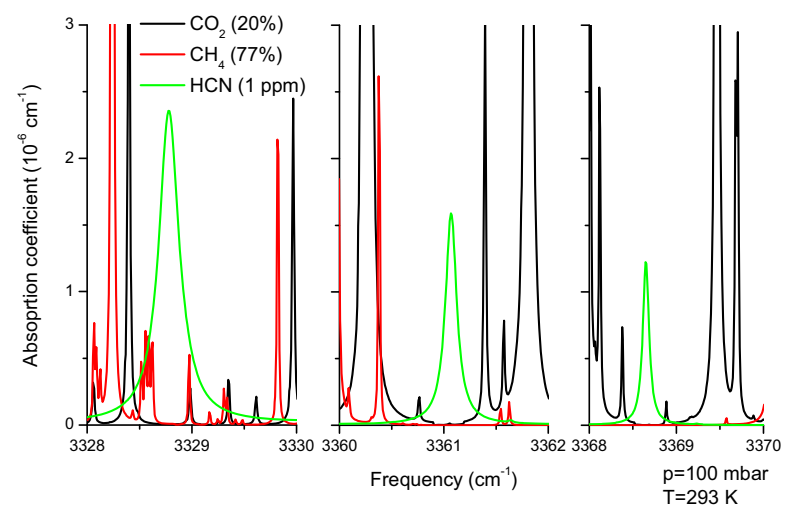

Figure 4. Three spectra of hydrogen cyanide in a synthetic biogas matrix [19]

\subsection{Carbon monoxide}

For carbon monoxide, two approaches are followed. The draft specifications for biomethane and upgraded biogas $[6,7]$ specify the gas chromatographic methods of ISO 6974 [21,22]. Not all GC configurations can be used for analysing carbon monoxide in biogas, because it often co-elutes with nitrogen. A suitable GC-method is developed, alongside an approach involving spectroscopy. The spectroscopic methods are interesting, because they would enable developing an on-line analyser capable of analysing a broad range of components, such as methane, carbon dioxide, water, ammonia, carbon monoxide, hydrogen chloride, and hydrogen cyanide. Components like nitrogen, hydrogen and oxygen cannot be detected when the analyser is based on infrared absorption. Nevertheless, such an analyser would be a significant step towards an easy-touse device that would also provide the data for calculating the biogas properties needed for fiscal metering, such as the calorific value, density, and Wobbe index [23]. The feasibility of developing such an instrument is part of ENG54 Biogas.

\section{Biogenic methane content}

One of the wishes of the European Commission is to have a method for determining the biogenic methane content in blends of gas from renewable sources and natural gas. The reason for this request is that the taxation of these gases is different, and then once blended there are currently no traceable methods for determining the biogenic methane content. The method is seen as a means to detect fraud in the trade of biomethane and upgraded biogas. In ENG54 Biogas, measurement standards are developed to support the GC/MS-based methods to measure the content of ${ }^{14} \mathrm{CH}_{4}$, containing an isotope of carbon $\left({ }^{14} \mathrm{C}\right)$ that can only originate from recent feedstocks [24]. The content of this isotopologue in natural gas is zero. The second approach involves the measurement of the isotopic signature of ${ }^{2} \mathrm{H} /{ }^{1} \mathrm{H}$ and ${ }^{13} \mathrm{C} /{ }^{12} \mathrm{C}$ to make the discrimination. The literature is unclear about the feasibility to discriminate between renewable and fossil gas on this basis.

\section{Moisture}


ENG01 GAS [11] successfully delivered new calibration facilities providing metrological traceability to dew-point measurements in methane in a pressure range up to 6 MPa [25]. Furthermore, a novel research facility was constructed and used for determining the water vapour enhancement factor in methane. The results obtained show that online water content / dew-point measurements are significantly affected by the matrix gas and the enhancement factor applied in the calculations. All the measurements were carried out in air, nitrogen or pure methane. ENG54 Biogas focuses on the effect of significant variations in the gas composition on the water vapour enhancement factor and on the performance of dew-point sensors. After minor modifications in the facilities, measurements are carried out with gas compositions and at pressures relevant to the biogas applications (e.g., $0.1 \mathrm{MPa}-60 \mathrm{MPa}$ ). The subsequent modelling leads to an accurate calculation method for the water vapour enhancement factor in biogas with varying gas composition which is not currently available, including the associated measurement uncertainty.

\section{Particulates}

The draft specifications for biomethane and upgraded biogas $[6,7]$ require the gas to be "technically free" from particulates. In the recent years, substantial progress has been made in measuring the particulate content of air, such as test methods for determining solid particle content in compressed air based on counting particles [26] and by mass concentration [27]. In ENG54 Biogas, work is done to assess to what extent these methods are applicable to biogas. Practically, the aim will be to maintain dust levels in biogas that do not exceed the ones in natural gas.

\section{Calorific value and density}

The measurement of the physical properties of nonconventional gases has been one of the aims of ENG01 GAS $[11,28]$. Accurate and traceable calorimeters were developed and validated by measuring the calorific value of non-conventional reference gas mixtures. Relative expanded uncertainties from $0.08 \%$ to $0.48 \%$ have been obtained for the reference calorimeter while uncertainties with field calorimeters range from $0.18 \%$ to $2.52 \%$ for the same mixtures. [29]. While the indirect method for the calorific value calculation of biogases (based on gas chromatographic composition measurement) [23] comes with substantially higher costs of ownership and is reported to suffer from reliability issues, calorimeters can be the solution for biogas producers and distributors seeking reliable energy measurements. A key issue is to optimise the combustion conditions for biogas at every stage of its purification and upgrading, to avoid biases in the calorific value, which leads to the wrong pricing of the biogas and biomethane delivered. The problem of combustion potentially due to various factors such as the level of impurities, the particle and water contents in the biogases is resolved by making significant improvements to the facilities validated in ENG01 GAS [11].

Traceable measurements of the key physical properties of biogas (e.g., calorific value, density, and Wobbe index) are urgently required. Complementary to the work on the calorific value, density calculations are improved by assessing the validity of the equations-ofstate used for this purpose [30].

\section{Sampling issues}

The sampling of biogas is a key and critical step in conformity assessment, in particular where it comes to sampling biogas for measuring the contents of impurities. Accurate and representative sampling is a prerequisite for having confidence in the results of analyses performed on biogas samples. Current methods for sampling reactive and unstable components in biogas give grossly inconsistent and unreliable results.

In preparation of experimental work to assess the suitability of sample cylinders, sorption tubes and sample bags with respect to the target impurities, a literature survey has been made to identify the most promising solutions [31]. Most of the work found in the literature focuses on VOCs and siloxanes in particular, and for example little is found about sampling for ammonia.

The planned experimental work will take advantage of the availability of novel measurement standards and methods and lead to a best practice guide on biogas sampling.

\section{Concluding remarks and outlook}

The preparation of the draft specifications for biogas and biomethane as developed in CEN/TC408 under the mandate $\mathrm{M} / 475$ is the first step into a process that eventually leads to a measurement infrastructure that facilitates the injection of biomethane and upgraded biogas into natural gas grids and for use as transport fuel $[6,7]$. The response from the metrology community in setting up a project to develop novel measurement standards and methods to address the demands of the industry in the form of ENG54 Biogas is an important second step. On the basis of the results of this project, services can be delivered such as certified reference materials, calibrations and proficiency testing schemes, that will greatly improve the measurement performance of laboratories testing biomethane and biogas, and where applicable, also those of online measurement systems. In doing so, implementing EN 1776 [32] for these renewable energy gases is brought a leap step forward.

The first results in ENG54 Biogas indicate that the project is well on target and leads to novel results. It is for example indeed feasible to use infrared spectroscopy for selected impurities, which so far has not been satisfactorily demonstrated for energy gases, which all have large absorptions in the infrared region.

\section{References}

1. Directive 2009/28/EC of the European Parliament and of the Council on the promotion of the use of energy from renewable sources, Brussels, 23 April 2009

2. COM (2010) 639, Energy 2020, A strategy for competitive, sustainable and secure energy

3. European Commission, Directorate-general for energy, M/475 EN, Mandate to CEN for standards for biomethane for use in transport and injection in natural gas pipelines, Brussels, 8 November 2010 
4. European Commission, Directorate-general for energy and transport, M/400 EN, Mandate to CEN for standardisation in the field of gas qualities, Brussels, 16 January 2007

5. Directive 2003/55/EC of the European Parliament and of the Council concerning the common rules for the internal market in natural gas, Brussels, 26 June 2003

6. prEN 16723-1 -- Natural gas and biomethane for use in transport and biomethane for injection in the natural gas network -- Part 1: Specifications for biomethane for injection in the natural gas network, Committee Draft, 2014

7. prEN 16723-2 -- Natural gas and biomethane for use in transport and biomethane for injection in the natural gas network -- Part 2: Automotive fuel specifications, Committee Draft, 2014

8. prEN 16726 -- Gas infrastructure -- Quality of gas -Group H, Committee Draft, 2014

9. A.M.H. van der Veen, K. Arrhenius, A. Murugan, C. Mandereau, M. Svensson, "Standardisation of methods for impurity contents in biomethane and upgraded biogas", Potential Research Topic, EMPIR call 2015 for pre- and co-normative research, http://msu.euramet.org/pre norm 2015/SRTs/SRTn05.pdf

10. European Metrology Research Programme, ENG54 Metrology for Biogas, http://projects.npl.co.uk/metrology-for-biogas/ and http://www.euramet.org/Media/docs/EMRP/JRP/JRP Summaries 2013/Energy_JRPs/ENG54_Publishabl e JRP Summary.pdf

11. A.S. Brown, D.N. Jones, M.J.T. Milton, M.L. Downey, G.M. Vargha, A.M.H. van der Veen, H. Ent, K. Arrhenius, D. Tuma, "Towards an European infrastructure for the characterisation of energy gases", Proc. $2^{\text {nd }}$ IMEKO TC 11 International Symposium Metrological Infrastructure, 2011

12. Evaluation of measurement data - The role of measurement uncertainty in conformity assessment JCGM 106:2012

13. F.R. Guenther, W.R. Miller, D.L. Duewer, G.S. Heo, Y.-D. Kim, A.M.H. van der Veen, L. Konopelko, Y. Kustikov, N. Shor, C. Brookes, M. Milton, F. Dias, H. Qiao, "International Comparison CCQM-K41: Hydrogen sulfide in nitrogen", Metrologia 44 (2007), Techn. Suppl. 08004

14. L. Culleton, "Reference gas standards and methods for the measurement of siloxanes and total silicon in biogas", Proc. $8^{\text {th }}$ International Gas Analysis Symposium \& Exhibition, Rotterdam, the Netherlands, 2015

15. L.A. Konopelko, Y.A. Kustikov, I.M. Vishnyakov, M.V. Pavlov, O.V. Efremova, Jin-Chun Woo, YongDoo Kim, R.M. Wessel, P.R. Ziel, M.J.T. Milton, G. Vargha, A. Brown, I. Uprichard, "The Final Report and the results of key comparison CCQM-K65: Gas standards containing methyl and ethyl mercaptans (at the level of $20-30 \mu \mathrm{mol} / \mathrm{mol}$ ) in methane", Metrologia 47 (2010) Tech. Suppl., 08004
16. ISO 6145 Gas analysis -- Preparation of calibration gas mixtures using dynamic volumetric methods (all parts), ISO, 2001-2014

17. ISO 6142 Gas analysis -- Preparation of calibration gas mixtures -- Gravimetric method, $2^{\text {nd }}$ edition, ISO, 2001

18. A.S. Brown, A. Murugan and R. J. C. Brown, "Measurement of 'total halogenated compounds' in hydrogen: is the ISO 14687 specification achievable?", Accred. Qual. Assur. 20 (2015) pp. 223-227.

19. Persijn S.T., Personal communication

20. S. Persijn, F. Harren, A. van der Veen, "Quantitative gas measurements using a versatile OPO-based cavity ringdown spectrometer and the comparison with spectroscopic databases", Applied Physics B 100 (2010), pp. 383-390

21. ISO 6974-1 -- Natural gas -- Determination of composition with defined uncertainty by gas chromatography -- Part 1: Guidelines for tailored analysis, $2^{\text {nd }}$ edition, ISO Geneva, 2012

22. ISO 6974-2 -- Natural gas -- Determination of composition with defined uncertainty by gas chromatography -- Part 2: Measuring-system characteristics and statistics for processing of data, $2^{\text {nd }}$ edition, ISO Geneva, 2012

23. ISO 6976 - Natural gas -- Calculation of calorific values, density, relative density and Wobbe index from composition, ISO Geneva, 1995

24. S.W.L. Palstra, H.A.J. Meijer, Biogenic carbon fraction of biogas and natural gas fuel mixtures determined with ${ }^{14} \mathrm{C}$, Radiocarbon, 56(1), (2014), pp. 7-28

25. R. Bosma, D. Mutter, A. Peruzzi, "Validation of Primary Water Dew-Point Generator for Methane at Pressures up to $6 \mathrm{MPa}$ ", International Journal of Thermophysics 35(6-7) (2014), pp. 738-747

26. ISO 8573-4, Compressed air — Part 4: Test methods for solid particle content, 2001

27. ISO 8573-8, Compressed air - Part 8: Test methods for solid particle content by mass concentration, 2004

28. F. Haloua, S.M. Sarge, T.E. Fernandez, C. García Izquierdo, J.J. Segovia C. Chamorro, M. Bozoianu, "Caloric quantities and density measurement of nonconventional gases", Proc. $2^{\text {nd }}$ IMEKO TC 11 International Symposium Metrological Infrastructure, 2011

29. F. Haloua, E. Foulon, E. El-Harti, S.M. Sarge, J. Rauch, M. Neagu, A.S. Brown, D. Tuma "Comparison of traceable methods for determining the calorific value of non-conventional fuel gases", Int. J. Thermal Sci., submitted

30. M.E. Mondéjar,T.E. Fernández-Vicente, F. Haloua, C.R. Chamorro, "Experimental determination of ( $p$, $\rho, T)$ properties for mixtures of carbon dioxide with methane for the thermodynamic characterization of non-conventional energy gases", J. Chemical \& Engineering Data, 2012, 57 (9) pp 2581-2588

31. K. Arrhenius, A.S. Brown, A.M.H. van der Veen, "Suitability of different containers for the sampling and storage of biogas and biomethane for the 
determination of the trace impurities - A review", Analytica Chimica Acta, submitted

32. EN 1776 Gas supply systems - Natural gas measuring stations - Functional requirements, Brussels, Belgium, 1998 